VÁSQUEZ-PORTOMEÑE, Fernando. "La circunstancia atenuante de embriaguez: una visión de sus elementos y requisitos en algunos sistemas penales iberoamericanos".

Polít. crim. Vol. 12, № 23 (Julio 2017), Art. 11, pp. 409-427.

[http://www.politicacriminal.cl/Vol_12/n_23/Vol12N23A11.pdf]

\title{
La circunstancia atenuante de embriaguez: una visión de sus elementos y requisitos en algunos sistemas penales iberoamericanos
}

\section{The attenuating circumstance of drunkenness: a vision of its elements and requirements in some Ibero-American penal systems}

\author{
Fernando Vázquez-Portomeñe Seijas \\ Profesor Titular de Derecho penal \\ Universidad de Santiago de Compostela \\ fernando.portomene@usc.es
}

\section{Resumen}

El objetivo primordial de este trabajo es realizar una aproximación a los elementos y requisitos de la atenuante de embriaguez en los Códigos penales de Uruguay, Venezuela y El Salvador, a partir de la doctrina y la jurisprudencia. En concreto, son objeto de estudio su fundamento, su conexión con el delito perpetrado, sus diferencias con las eximentes vinculadas a la intoxicación etílica y la posibilidad de apreciar la atenuante analógica.

Palabras clave: Embriaguez, circunstancias atenuantes, Uruguay, Venezuela, El Salvador.

\begin{abstract}
The aim of this work is to study the elements of the attenuating circumstance of the drunkenness in the Penal Codes of Venezuela, Uruguay and El Salvador, taking as staring point the doctrinal and jurisprudential interpretations. Particular attention is being paid to its legal basis, the connection with the commission of the offence, its differences with the extenuating circumstances and the possibility of applying the analogical circumstance.
\end{abstract}

Key words: Drunkenness, attenuating circumstances, Uruguay, Venezuela, El Salvador.

\section{Introducción.}

La edición 2014 del Reporte de Economía y Desarrollo (RED) del Banco de Desarrollo de América Latina sienta la tesis de que el uso problemático de alcohol y drogas ilícitas está asociado a mayores tasa de criminalidad, y aporta el sugerente resultado de la encuesta CAF de 2013, realizada en las principales ciudades latinoamericanas, relativo a que entre el 20 y el $50 \%$ de las víctimas que llegaron a ver a su/s victimario/s pensaban que, en el momento de la agresión, estos se hallaban bajo los efectos de dichas sustancias ${ }^{1}$.

\footnotetext{
${ }^{1}$ Vid. BANCO DE DESARROLLO DE AMÉRICA LATINA, Por una América Latina más segura: Una nueva perspectiva para prevenir y controlar el delito, Bogotá: CAF, 2014, pp. 83 y 84.
} 
VÁSQUEZ-PORTOMEÑE, Fernando. "La circunstancia atenuante de embriaguez: una visión de sus elementos y requisitos en algunos sistemas penales iberoamericanos".

Los hallazgos del RED no pueden sorprender. Bien al contrario, la relación existente entre el consumo de alcohol y la delincuencia es, desde hace décadas, un tópico en numerosos estudios y análisis correspondientes a ámbitos tan variados como la psicología, la sociología, la medicina legal, la criminología o el Derecho penal ${ }^{2}$.

El objeto de este trabajo es, precisamente, examinar los elementos y requisitos básicos de la atenuante de embriaguez en tres sistemas penales que acogen concepciones diversas de la misma: los de Venezuela, Uruguay y El Salvador. De entre ellos, es, probablemente, el venezolano el que presenta rasgos más peculiares. En un país en el que, como se ha escrito, se bebía "de forma exagerada", el legislador penal optó por reprimir "la disposición que genera el licor hacia la violencia" con soluciones particularmente severas ${ }^{3}$, como la elevación de la pena de un quinto a un tercio adicional si el imputado utiliza la ingesta para facilitarse la realización del delito o para prepararse una excusa. Los casos de Uruguay y El Salvador no ofrecen menos interés, teniendo en cuenta que, en ambos países, el abuso de alcohol puede fundamentar claramente tanto la aplicación de una atenuante como la de una eximente y que no siempre resulta sencillo delimitar y establecer con precisión los ámbitos de aplicación de una y otra ${ }^{4}$.

\footnotetext{
${ }^{2}$ Precisamente, algunas de las conclusiones alcanzadas en esos otros campos son extraordinariamente interesantes para el Derecho penal. Se ha demostrado, por ejemplo, que las expectativas que generan las propiedades desinhibidoras del alcohol son tan poderosas como el efecto farmacológico en si mismo, lo que permitiría sustentar la tesis de que los agresores recurren a él para justificar su comportamiento: vid. MARLATT, Gordon Alan; ROSENHOW, Damaris, "Cognitive processes in alcohol use: Expectancy and the balanced placebo design", en: MELLO, Nancy (Ed.), Advances in substance abuse: Behavioural and biological research, Greenwich: JAI Press, 1980, pp. 159-199. Se ha alertado, también, sobre los riesgos de utilización de las denominadas "técnicas de autojustificación", que sirven para legitimar los comportamientos violentos y paralizan la intervención del sistema legal con argumentos y coartadas como su atribución a factores psicopatológicos individuales (por ejemplo, a la influencia del alcohol): vid., sobre ellas, GARCÍA PABLOS DE MOLINA, Antonio, Criminología. Una introducción a sus fundamentos teóricos, $7^{\mathrm{a}}$ ed., Valencia: Tirant lo Blanch, 2013, pp. 156-157. A este último respecto, debe decirse que la literatura especializada ha venido abundando en la relación existente entre el abuso de alcohol y la violencia, concluyendo que, aunque no es su causa (ni una de sus causas), sí interviene como facilitador de las agresiones, ), juntamente con otras características o variables individuales (la depresión y los trastornos psicológicos, las alteraciones en los estados de ansiedad, la autoestima, la impulsividad...) y contextuales (la carencia de una red adecuada que proporcione apoyo social, el estatus socio-económico, la condición de inmigrante...) (Vid. GELLES, Richard; STRAUS, Murray, Intimate violence. The causes and consequences of abuse in the American family, Nueva York: Simon \& Schuster, 1988, pp. 45 y 46, QUIGLEY, Brian; LEONARD, Kenneth, "Alcohol Use and Violence Among Young Adults", Alcohol Research \& Health, Vol. 38, $\mathrm{N}^{\mathrm{o}} 4$ (2005), pp. 191-194, p. 192, nota $\mathrm{n}^{\mathrm{o}}$ 23; ECHEBURÚA ODRIOZOLA, Enrique, "Tratamiento psicológico a los hombres violentos contra la pareja", Cuadernos de Derecho Judicial, No 2 (2005), pp. 157178, p.160; RUIZ PÉREZ, Isabel; BLANCO PRIETO, Pilar; VIVES CASES, Carmen, "Violencia contra la mujer en la pareja: determinantes y respuestas sociosanitarias", Gaceta Sanitaria, Vol. 18 (2004), pp. 4-12, p. 6; CATALÁ MIÑANA, Alba; LILA, Marisol; OLIVER, Amparo, "Consumo de alcohol en hombre penados por violencia contra la pareja: factores individuales y contextuales", Adicciones, Vol. $25 \mathrm{~N}^{\circ} 1$ (2013), pp. 1928 , p. 20, nota $\mathrm{n}^{\mathrm{o}} 23$, con numerosas indicaciones bibliográficas. En la doctrina penal destacan esa clase de interacciones, entre otros autores, LAURENZO COPELLO, Patricia, "Violencia de género y derecho penal de excepción: entre el discurso de la resistencia y el victimismo punitivo", Cuadernos de Derecho judicial, № 9 (2007), pp. 31-74, p. 63.

${ }^{3}$ Cfr. ESCALANTE, Ramón A., La defensa del enfermo mental en el nuevo proceso penal venezolano, Caracas: Vadell Hermanos Editores, 2001, pp. 124-126.

${ }^{4}$ La jurisprudencia salvadoreña ha puesto especial énfasis en la importancia de esa tarea de delimitación: vid., entre otras, las sentencias de la Sala de lo Penal de la Corte Suprema de Justicia 286-CAS-2011, de 25 de
} 
Polít. crim. Vol. 12, No 23 (Julio 2017), Art. 11, pp. 409-427.

[http://www.politicacriminal.cl/Vol_12/n_23/Vol12N23A11.pdf]

Avanzo ya desde este momento que mi pretensión no es la de adentrarme en cuestiones de índole criminológica, sociológica o político-criminal. Tampoco me detendré en los problemas que plantea la apreciación de la atenuante en la comisión de determinados delitos o grupos de delitos ${ }^{5}$, ni en su relación e implicaciones con la construcción dogmática de la actio libera in causa ${ }^{6}$. He preferido ceñirme al estudio de su definición legal en los Códigos penales de los tres países -es decir, en los artículos 29.1 del de El

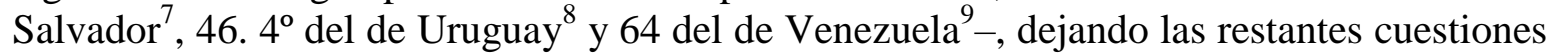
para un estudio posterior.

octubre de 2013, y 441-CAS-2009, de 6 de mayo de 2011. En la doctrina pueden verse, entre otros autores, CAIROLI MARTÍNEZ, Milton, "La capacidad de culpabilidad y su exclusión (inimputabilidad)", en: ARROYO ZAPATERO, Luis Alberto; BERDUGO GÓMEZ DE LA TORRE, Ignacio (Coords.), Homenaje al Dr. Marino Barbero Santos: "in memoriam", Salamanca: Universidad de Salamanca, 2001, pp. 896-906, p. 906; MORENO CARRASCO, Francisco; RUEDA GARCÍA, Luis, Código penal de El Salvador comentado, t. I, San Salvador: Consejo Nacional de la Judicatura, 2011, p 172; SCAPUSIO, Beatriz, PREZA RESTUCCIA, Dardo, LANDEIRA, Raquel, "Proyecto de reforma del proceso penal", Revista de la Facultad de Derecho de la Universidad de la República, № 27 (2008-2009), pp. 237-252, pp. 246-247; ARTEAGA SÁNCHEZ, Alberto, Derecho penal venezolano, 10a ed., Caracas: Mcgraw-Hill Interamericana, 2006, pp. 337 y ss.; CASAROTTI, Humberto, "Problemas que la drogas plantea al psiquiatra práctico", Revista de Psiquiatría de Uruguay, Vol. 72 (2008), pp. 186-197, p. 194. En España la bibliografía ha examinado esta cuestión tomando como punto de partida la decisión del legislador de tipificar como atenuante la grave adicción al alcohol o a las drogas (art. 21. $2^{\mathrm{a}} \mathrm{CP}$ ): vid. CORCOY BIDASOLO, Mirentxu; MIR PUIG, Santiago (Dirs.), Comentarios al Código penal. Reforma LO 5/2010, Valencia: Tirant lo Blanch, 2011, p. 234; LÓPEZ BARJA DE QUIROGA, Jacobo, Tratado de Derecho penal. Parte General, Madrid: Civitas, 2010, p. 825; PUENTE SEGURA, Leopoldo, Circunstancias eximentes, atenuantes y agravantes de la responsabilidad criminal, Madrid: Colex, 1997, pp. 361-362; VALLE MUÑIZ, José Manuel; QUINTERO OLIVARES, Gonzalo, en: QUINTERO OLIVARES, Gonzalo (Dir.), Comentarios al Nuevo Código Penal, Pamplona: Aranzadi, 1996, p. 281; QUINTERO OLIVARES, Gonzalo, Parte General del Derecho penal, $4^{\text {a }}$ ed., Pamplona: Aranzadi, 2014, p. 790.

${ }^{5}$ Me refiero, en particular, a los delitos contra la salud pública y la seguridad de tráfico y a los de violencia doméstica y contra la mujer.

${ }^{6}$ Sobre dicha figura vid, en profundidad, SILVA SÁNCHEZ, Jesús María, "La estructura de la 'actio libera in causa' en los delitos cometidos bajo un síndrome de abstinencia de drogas (Una visión crítica de la última doctrina jurisprudencial), La Ley, $\mathrm{N}^{\circ} 1$ (1988), pp. 910-918; JOSHI JUBERT, Ujala, La doctrina de la "actio libera in causa" en Derecho penal, Barcelona: Bosch, 1992; ALCÁCER GUIRAO, Rafael, "Actio libera in causa" dolosa e imprudente: la estructura temporal de la responsabilidad penal, Barcelona: Atelier, 2005; DOLD, Dennis, "Die actio libera in causa als Sonderfall der mittelbaren Täterschaft", Goltdammer's Archiv für Strafrecht, Vol. 155, № 7 (2008), pp. 427-441.

${ }^{7}$ Dicho precepto le atribuye efectos atenuantes al hecho de "estar el culpable en estado de intoxicación alcohólica o de otra índole que, sin ser preordenada al hecho, no llegue a tener plenitud de efectos sobre el sujeto".

${ }^{8}$ A su tenor, es circunstancia que atenúa la responsabilidad penal "la embriaguez voluntaria y la culpable. La embriaguez voluntaria que no fuere premeditada para cometer el delito, y la culpable plenas, y la producida por fuerza mayor o caso fortuito".

${ }^{9} \mathrm{Su}$ contenido es el que sigue: "Si el estado de perturbación mental del encausado en el momento del delito proviniere de embriaguez, se seguirán las reglas siguientes: 1.- Si se probare que, con el fin de facilitarse la perpetración del delito, o preparar una excusa, el acusado había hecho uso del licor, se aumentara la pena que debiera aplicársele de un quinto a un tercio, con tal que la totalidad no exceda del maximum fijado por la ley a este género de pena. Si la pena que debiere imponérsele fuere la de presidio, se mantendrá esta. 2.- Si resultare probado que el procesado sabia y era notorio entre sus relaciones que la embriaguez le hacía provocador y pendenciero, se le aplicaran sin atenuación las penas que para el delito cometido establece este Código. 3.- Si no probada ninguna de las dos circunstancias de los dos números anteriores, resultare demostrada la perturbación mental por causa de la embriaguez, las penas se reducirán a los dos tercios, 
VÁSQUEZ-PORTOMEÑE, Fernando. "La circunstancia atenuante de embriaguez: una visión de sus elementos y requisitos en algunos sistemas penales iberoamericanos".

En cuanto a la metodología empleada, he trabajado, como acabo de indicar, con el derecho positivo, así como con las doctrinas y jurisprudencias nacionales, recurriendo siempre a una perspectiva de derecho comparado, que me permitiese establecer las semejanzas y diferencias existentes entre los tres sistemas penales. Como recurso jurisprudencial me he servido de las siguientes bases de datos: la de la Jurisprudencia Nacional Pública del Poder Judicial de Uruguay (http://bjn.poderjudicial.gub.uy/BJNPUBLICA/busquedaSimple.seam), la del Centro de Documentación Judicial de la Corte Suprema de Justicia de El Salvador (http://www.jurisprudencia.gob.sv/VisorMLX/Documento/BusquedaLibre.aspx?baseId=1) y, finalmente, la del Tribunal Supremo de Justicia de Venezuela (http://www.tsj.gob.ve/es/web/tsj/juriprudencias).

Por lo que se refiere a la organización de los contenidos del estudio, me he centrado, en primer lugar, en el fundamento de la atenuante. A continuación he tratado su estructura y sus elementos, y he dejado para el final su relación con las eximentes relacionadas con el abuso de alcohol y la posibilidad de acudir a una atenuante analógica a la ordinaria. Los resultados de la investigación se han plasmado en sendos cuadros comparativos, que incluyen una breve descripción del marco legal de cada país (Tabla 1) y la relación de la atenuante con las eximentes directa e indirectamente relacionadas con ella (Tabla 2).

\section{Aproximación general a la atenuante de embriaguez.}

\subsection{Fundamento y naturaleza.}

Uno de los elementos más relevantes en la interpretación de la atenuante de embriaguez es el de su fundamento. Tanto la jurisprudencia como la doctrina de los tres países lo asocian a un déficit de culpabilidad, derivado del hecho de que el sujeto ha delinquido en un estado de perturbación mental causado, justamente, por la intoxicación alcohólica ${ }^{10}$. Existe

sustituyéndose la prisión al presidio. 4.- Si la embriaguez fuere habitual, la pena corporal que deba sufrirse podrá mandarse cumplir en un establecimiento especial de corrección. 5.- Si la embriaguez fuere enteramente casual o excepcional, que no tenga precedente, las penas en que haya incurrido el encausado se reducirán de la mitad a un cuarto, en su duración, sustituyéndose la pena de presidio con la de prisión”.

10 Véanse las siguientes sentencias de la Sala de Casación Penal del Tribunal Supremo de Justicia de Venezuela: 0243/C00-1396, de 3 de abril de 2001; 306/C09-214, de 27 de julio; 357/C10-073, de 6 de agosto de 2010; 495/C10-248, de 1 de diciembre de 2011; 634/C99-1376, de 11 de mayo. Todas ellas destinan la atenuante a sujetos a los que, por su actitud en el momento de embriagarse, no cabría reprocharles, en absoluto, el hecho realizado. También la jurisprudencia salvadoreña deja sentada la idea de que, aunque la ebriedad no implica un estado de inimputabilidad, disminuye los frenos inhibitorios del sujeto, "por lo que sí es dable colegir una disminución en el reproche por su hechos": vid. sentencia 121-93-2001 del Tribunal Sexto de Sentencia de San Salvador, de11 de septiembre de 2001; sentencia 286-CAS-2011, de la Sala de lo Penal de la Corte Suprema de Justicia, de 25 de octubre de 2013. Por su parte, en la jurisprudencia uruguaya trabajan con esa misma idea, por ejemplo, la sentencia 509/2010 de la Suprema Corte de Justicia, de 1 de septiembre de 2010, así como las siguientes sentencias del Tribunal de Apelaciones de lo Penal: 268/2011, de 4 de agosto; 190/2011, de 15 de diciembre; 124/2013, de 20 de junio; 55/2014, de 13 de marzo. Por lo que se refiere a la literatura penal, destacan la íntima relación existente entre la embriaguez y la imputabilidad, en Venezuela, CHIOSSONE, Tulio, Manual de Derecho penal venezolano, Caracas: Universidad Central de Venezuela, 1981, p. 119; FRÍAS CABALLERO, Jorge, Problemas de culpabilidad en el Código penal venezolano, Caracas: Editores individuales 3, 1988, p. 137; MENDOZA TROCONIS, José Rafael, Curso de 
Polít. crim. Vol. 12, № 23 (Julio 2017), Art. 11, pp. 409-427.

[http://www.politicacriminal.cl/Vol_12/n_23/Vol12N23A11.pdf]

consenso, pues, en torno a que lo que le da sentido a la atenuación no es la ebriedad por si sola, sino su incidencia en la motivación, la imputabilidad y la capacidad de conocimiento de la ilicitud. Nos hallamos, así, ante una circunstancia de naturaleza subjetiva, personal, no transmisible a los partícipes $^{11}$, que desempeña un papel relevante a la hora de graduar los efectos de los déficits de imputabilidad en el sistema penal, situándose a medio camino entre diversas eximentes relacionadas con la alteración de la conciencia, la perturbación mental y la propia embriaguez (completa) ${ }^{12}$, por una parte, y el simple descontrol o excitación, por otra ${ }^{13}$.

Como puede verse, el planteamiento que acabo de recoger no se aparta de la tendencia (mayoritaria) a vincular las circunstancias modificativas de la responsabilidad criminal a la teoría jurídica del delito y a presentarlas, por consiguiente, como una forma de concreción de los presupuestos valorativos en que se asienta ${ }^{14}$. Ahora bien, a partir de él parecen

Derecho penal venezolano: Parte General, $7^{\text {a }}$ ed., Caracas: Librería Destino, 1996, pp. 22 y ss.; ESCALANTE, La defensa del enfermo mental, cit., nota $n^{\circ} 3$, p. 130; ARTEAGA SÁNCHEZ, Alberto, Derecho penal venezolano, cit. nota $\mathrm{n}^{\circ}$ 4, pp. 337 y 338. En la doctrina uruguaya, OTTATI FOLLE, Amadeo, Alcoholismo y Derecho penal, Montevideo: Amalio M. Fernández, 1975, pp. 71 y 80, a pesar de reconocer que las soluciones del legislador uruguayo obedecen, más que nada, a "razones de política criminal". Por último, en la salvadoreña, MORENO CARRASCO/RUEDA GARCÍA, Código penal, cit. nota no 4, p. 172. En la doctrina española sostienen esa misma postura, a propósito de la atenuante segunda, ARROYO DE LAS HERAS, Alfonso; MUÑOZ CUESTA, Javier; GOYENA HUERTA, Jaime, Las circunstancias atenuantes en el Código penal de 1995, Pamplona: Aranzadi, 1997, pp. 92-93; PADILLA ALBA, Herminio Ramón, Exención y atenuación de la responsabilidad penal por consumo de drogas, Granada: Comares, 2001, p. 202 y nota 47; ARIAS EIBE, Manuel José, Responsabilidad criminal. Circunstancias modificativas y su fundamento en el Código penal. Una visión desde la doctrina y la jurisprudencia del Tribunal Supremo, Barcelona: Bosch, 2007, pp. 213-214; ROMÁN PINA-FUSTER, Román, Embriaguez, alcoholismo y Derecho penal, Barcelona: Bosch, 2000, pp. 80 y 81; CASTELLÓ NICÁS, Nuria, "Causas de inimputabilidad: drogadicción”, Estudios de Derecho Judicial, No 110 (2006), pp. 369-450, p. 430.

${ }^{11}$ Vid., en este sentido, SUÁREZ-MIRA RODRÍGUEZ, Carlos, La imputabilidad del consumidor de drogas, Valencia: Tirant lo Blanch, 2000, pp. 213 y 220; MARÍN DE ESPINOSA CEBALLOS, Elena Blanca, en: ZUGALDÍA ESPINAR, José Miguel (Dir.), Derecho penal, Parte General, 2a ed., Valencia: Tirant lo Blanch, 2004, p. 882.

${ }^{12}$ Vid. infra apartado 3.

${ }^{13}$ La sentencia 286-CAS-2011 de la Sala de lo Penal de la Corte Suprema de Justicia de El Salvador, de 25 de octubre de 2013, explica con detalle la graduación a que se alude en el texto. Vid. también VEGA GUTIÉRREZ, José Zamyr, "La intoxicación por bebidas alcohólicas en el Derecho penal", El nuevo diario, 19 de agosto de 2011; ROMÁN PINA-FUSTER, Embriaguez, cit. nota no 10, p. 80; OBREGÓN GARCÍA, Antonio, "La eximente del art. 20.2, inciso $1^{\circ}$, CP: Estado de intoxicación plena por consumo de alcohol u otras drogas", Estudios de Derecho Judicial, № 110 (2006), pp. 137-218, p. 145, quien indica que "debido al carácter gradual o progresivo de los efectos del alcohol, el sujeto sigue conservando -hasta que alcanza una elevada perturbación- la facultad de idear acciones delictivas y la capacidad física para realizarlas". El artículo 64.2 del Código Penal venezolano establece expresamente que "si resultare probado que el procesado sabía y era notorio entre sus relaciones que a embriaguez le hacía provocador y pendenciero, se le aplicarán sin atenuación las penas que para el delito cometido establece este Código".

${ }^{14}$ En la doctrina española sostienen esa misma postura, a propósito de la atenuante segunda, PADILLA ALBA, Exención y atenuación, cit. nota n ${ }^{\circ} 10$, p. 202, nota n 47; ROMÁN PINA-FUSTER, Embriaguez, cit. nota $\mathrm{n}^{\circ} 10$, pp. 80-81. Sobre la discusión existente en torno al fundamento dogmático de las circunstancias y las diversas posiciones doctrinales al respecto vid. GONZÁLEZ CUSSAC, José Luis, Teoría general de las circunstancias modificativas de la responsabilidad criminal, Valencia: Tirant lo Blanch, 1988, pp. 53 y ss.; PUENTE SEGURA, Leopoldo, Circunstancias eximentes, atenuantes y agravantes de la responsabilidad criminal, Madrid: Colex, 1997, p. 313; SALINERO ALONSO, Carmen, Teoría general de las circunstancias 
VÁSQUEZ-PORTOMEÑE, Fernando. "La circunstancia atenuante de embriaguez: una visión de sus elementos y requisitos en algunos sistemas penales iberoamericanos".

abrirse dos líneas interpretativas diferenciadas: una más restrictiva, que califica con arreglo a la atenuante los supuestos en que el sujeto ve efectivamente mermadas sus capacidades de conocer y autodeterminarse en el momento de ejecutar el hecho delictivo, y una segunda que, tras verificar la concurrencia de su presupuesto (la embriaguez), no entra ya a considerar si ha quedado demostrada dicha afección.

La primera es la aceptada por la jurisprudencia dominante, quizá, en los tres países, que requiere que, de una manera u otra, la afección a la imputabilidad forme parte de los hechos probados, por medio de elementos (fundamentalmente informes forenses y periciales) que acrediten que las capacidades de entender y/o querer del acusado se encontraban alteradas en el momento de la comisión de los hechos ${ }^{15}$. En apoyo de esa exigencia suele traerse el doble argumento de que para entender disminuida la imputabilidad se precisa algo más que la mera ingesta de bebidas alcohólicas y de que el hábito de consumirlas, en una u otra escala, no es indicativo, en absoluto, del estado del sujeto en el momento de ejecutar el delito. La jurisprudencia de la Sala de Casación Penal del Tribunal Supremo de Justicia de Venezuela ofrece ejemplos muy gráficos de este punto de vista. La sentencia 357/C10-073, de 6 de agosto de 2010, por ejemplo, desecha la atenuante al no constar en el expediente "la prueba de experticia demostrativa del grado de embriaguez", ni haberse demostrado en autos "que tal estado de embriaguez fuere capaz de generar un estado de perturbación mental suficiente de su conciencia y de sus actos", todo ello a pesar de que "en las actas que conforman el presente expediente cursan las declaraciones de los ciudadanos..., señalando que... (el acusado) había estado consumiendo licor desde tempranas horas". En el mismo sentido se pronuncia la 495/C10-248, de 1 de diciembre de 2011, desestimándola al resultar negativo el informe pericial toxicológico en sangre y orina y no constar, en autos, prueba demostrativa alguna de que el estado de embriaguez sufrido por el sujeto "fuere capaz de generar un estado de perturbación mental suficiente de su conciencia y de sus actos". Estos pronunciamientos parten, por consiguiente, de la base de que debe acreditarse la concreta e individualizada situación del sujeto en el momento comisivo, en lo concerniente a la influencia del alcohol sobre las facultades intelectuales y volitivas, entendiéndose, en otro caso, que el tribunal carece de los elementos de juicio necesarios para rebajar la pena.

Por contra, algunas decisiones del Tribunal de Apelaciones de lo Penal de Uruguay parecen dar por sentado que cualquier sujeto alcoholizado muestra, por ese mismo hecho, alguna clase de alteración de sus facultades psíquicas. En ellas, la aplicación de la circunstancia no requiere ninguna constatación de que el consumo abusivo de alcohol haya causado un

modificativas de la responsabilidad criminal y artículo 66 del Código penal, Granada: Comares, 2000, p. 65; ARIAS EIBE, Responsabilidad criminal, cit. nota n $^{\mathbf{1}} 10$, pp. 89 y ss.

${ }^{15}$ Vid., en la jurisprudencia uruguaya, las siguientes sentencias del Tribunal de Apelaciones de lo Penal: 311/2013, de 19 de noviembre; 94/2014, de 8 de abril; 96/2015, de 17 de abril; 174/2008, de 22 de julio de 2008; 124/2013, de 20 de junio de 2013. En la jurisprudencia venezolana, además de las citadas en el texto, pueden verse las siguientes sentencias de la Sala de Casación Penal del Tribunal Supremo de Justicia: 0243/C00-1396, de 3 de abril de 2001; 306/C09-214, de 27 de julio de 2010. Sin embargo, la sentencia 86CAS-2011, de 25 de octubre de 2013, de la Sala de lo Penal de la Corte Suprema de Justicia de El Salvador deduce la afectación parcial de las capacidades intelectivas y volitivas del sujeto del hecho de que, a pesar de haber ingerido alcohol, perpetró el hecho con el modus operandi propio de quien "aún tenía cierto conocimiento de su proceder en ese momento...". 
Polít. crim. Vol. 12, № 23 (Julio 2017), Art. 11, pp. 409-427.

[http://www.politicacriminal.cl/Vol_12/n_23/Vol12N23A11.pdf]

deterioro significativo de las facultades volitivas e intelectivas ${ }^{16}$. Su fundamento sería una suerte de presunción legal, avalada por la experiencia y los conocimientos científicos, de que toda embriaguez influye necesariamente en la capacidad volitiva o intelectiva del sujeto, restringiendo de manera apreciable sus facultades de control o inhibición. Podemos ver ese planteamiento en las sentencias 80/2015, de 20 de mayo -a cuyo tenor la presencia de un elevado nivel de alcohol en sangre obliga a asumir "que en el suceso la ingesta alcohólica tuvo una importante incidencia, exacerbó las conductas personales e hizo disminuir la apreciación de la magnitud de la conducta desarrollada"- y 308/2011, de 17 de noviembre -que hace uso de la atenuante aunque lo único que constaba en autos eran las declaraciones de los acusados y de un grupo de personas que no los habían visto "tremendamente alcoholizados"-. Otra de las que auspicia su aplicación sin tomar en consideración, realmente, la afección de dichas capacidades, es la sentencia sentencia18/2014, de 18 de febrero, que se ampara, además de en las declaraciones del acusado ("había bebido varias cervezas a lo largo de toda la noche"), en las de la doctora que lo asistió tras su detención ("tenía la mirada como ida... problemas de drogas o... alguna psicopatía") ${ }^{17}$. En general, esta otra construcción de la embriaguez permite soslayar las (considerables) dificultades que plantea acreditar el impacto de la ingesta en las psique del sujeto (en particular cuando no ha sido objeto de un reconocimiento médico inmediato $^{18}$ ), si bien, en mi opinión, propicia un cierto solapamiento de su campo de aplicación con los de la atenuante analógica y de las eximentes, asimismo, relacionadas con la intoxicación, ajustándose peor a los postulados de seguridad jurídica que deben presidir el sistema penal.

Al margen del déficit de imputabilidad, algunos de los autores que se han venido considerando en este trabajo sugieren un segundo fundamento, relacionado con los impulsos que se esconden tras los delitos cometidos por causa de la dependencia alcohólica $^{19}$. A mi modo de ver, sin embargo, no resulta correcto apelar a la incidencia de la embriaguez en ese terreno (el de la exigibilidad), por mucho que pueda acarrear la

\footnotetext{
${ }^{16}$ Vid. sentencia 96/2015 del Tribunal de Apelaciones de lo penal, de 17 de abril.

${ }^{17}$ En un sentido semejante se orientan la sentencia del Tribunal de Apelaciones de lo Penal de Uruguay 165/2013, de 17 de junio, que aprecia la atenuante argumentando que, aunque durante la instrucción no se le hubiese preguntado al imputado "cuánto había tomado, si lo hacía de rutina o los efectos del alcohol en su personalidad", "tanto en su primer declaración como en la reconstrucción, atribuyó importancia a la embriaguez para la ocurrencia del desenlace".

${ }^{18}$ Incide en ello CASTELLÓ NICÁS, "Causas de inimputabilidad", cit. nota no 10, pp. 424 y 430.

${ }^{19}$ Vid. MORENO CARRASCO/RUEDA GARCÍA, Código penal, cit. nota no 4, p. 174. En España son partidarios de esta interpretación de la atenuante segunda ROPERO CARRASCO, Julia; ZAMORANO MORENO, Pilar, "Las circunstancias atenuantes de la responsabilidad penal", Studia Carande, Vol. 5 (2000), pp. 115-140, p. 126; LORENZO SALGADO, José Manuel, "Imputabilidad, suspensión de la ejecución de la pena y cumplimiento de la condena”, en: BECOÑA IGLESIAS, Elisardo; RODRÍGUEZ LÓPEZ, Antonio; SALAZAR BERNARD, Isabel (Coord.), Drogodependencias V. Avances 1999, Santiago de Compostela: Universidad de Santiago de Compostela, 1999, pp. 15-55, pp. 35-36; MARTíNEZ GARAY, Lucía, La imputabilidad penal: concepto, fundamento, naturaleza jurídica y elementos, Valencia: Tirant lo Blanch, 2005, pp. 440 y ss. En la jurisprudencia española trasladan el centro de gravedad dela atenuante segunda desde el terreno de la afección a la imputabilidad al de la compulsión a delinquir, entre otras, las siguientes resoluciones del Tribunal Supremo: STS de 2 de marzo de 2006, STS de 20 de marzo de 2013, STS de 15 de abril de 2013, STS de 28 de junio de 2013 y STS de 22 de julio de 2013.
} 
VÁSQUEZ-PORTOMEÑE, Fernando. "La circunstancia atenuante de embriaguez: una visión de sus elementos y requisitos en algunos sistemas penales iberoamericanos".

aparición de un síndrome de abstinencia y conducir, incluso, al aislamiento o a la marginación social. Dos son los argumentos que permiten sostener esta idea.

El primero de ellos tiene que ver con la propia descripción legal de la circunstancia. El Código penal uruguayo alude a la necesidad de que el delito se ejecute "en estado de embriaguez, cuando esta no fuere habitual o posterior al proyecto de cometer el delito" 20 . Los de El Salvador y Venezuela se refieren expresamente los efectos psicológicos que puedan o deban derivarse de la intoxicación. Ninguno, por consiguiente, apunta a la embriaguez como estímulo inmediato para la comisión de un delito. Siendo así, lo más razonable $-\mathrm{y}$ respetuoso con el principio de legalidad- será pensar que su fundamento estriba, pura y simplemente, en sus efectos sobre las facultades de comprensión y autodeterminación del sujeto.

Por otra parte, si su radio de acción no se circunscribe, en ningún caso, a los delitos asociados a la obtención de las sustancias de que depende el sujeto, lo razonable será identificarla con un problema que puede incidir en la realización de cualquier actuación delictiva: un estado de imputabilidad disminuida por alteración de las capacidades volitivas e intelectivas ${ }^{21}$.

En suma, no hay duda de que el elemento teleológico de la atenuante de embriaguez en los Códigos penales de Uruguay, El Salvador y Venezuela presenta una única vertiente: la relativa a su incidencia en las facultades que permiten ajustar la voluntad a los requerimientos de la norma y motivarse con arreglo a ella. $\mathrm{Su}$ aplicación debe resolverse, pues, en función de la incidencia del alcohol en las facultades intelectivas y volitivas del sujeto, so pena de convertirla en una circunstancia de aplicación aritmética, vinculada a los grupos de población que, en uno u otro momento, hayan podido tener contacto con el alcohol. Los tres textos punitivos favorecen esa interpretación, al incorporar siempre una mención a sus efectos sobre el sujeto, sea directamente (El Salvador y Venezuela), sea indirectamente (Uruguay).

\subsection{Análisis de los elementos de la atenuante.}

La atenuante se compone, principalmente, de tres elementos: dos de carácter expreso (una situación de embriaguez derivada de la ingesta de bebidas alcohólicas y la exigencia de que dicha situación no haya sido buscada o "preordenada" a la realización del hecho delictivo de que se trate) y otro que se halla implícito en los tres códigos penales (la existencia de una determinada relación entre la embriaguez y la ejecución del delito). A ellos se añade, en Venezuela, otro de carácter negativo: que no resultase probado que el procesado "sabía y era notorio entre sus relaciones que la embriaguez le hacía provocador y pendenciero" "22. A

\footnotetext{
${ }^{20}$ La jurisprudencia explica la exclusión de la embriaguez habitual del ámbito de aplicación de la atenuante argumentando que "el hábito alcohólico debe tomarse como un antecedente personal indicativo de la antisocialidad y peligrosidad del agente". Cfr. sentencia 340/2007, del Tribunal de Apelaciones de lo Penal, de 8 de octubre de 2007, aportando ulteriores referencias jurisprudenciales.

${ }^{21}$ Vid. este mismo razonamiento en ARROYO DE LAS HERAS/MUÑOZ CUESTA/GOYENA HUERTA, Las circunstancias, cit. nota $\mathrm{n}^{\mathrm{o}} 10$, p. 92.

${ }^{22}$ Cfr. art. 64.2 del Código penal.
} 
Polít. crim. Vol. 12, No 23 (Julio 2017), Art. 11, pp. 409-427.

[http://www.politicacriminal.cl/Vol_12/n_23/Vol12N23A11.pdf]

continuación analizaré los tres primeros, los comunes a los tres textos legales, con la finalidad de establecer las semejanzas y diferencias existentes entre ellos.

\subsubsection{La embriaguez.}

El término recogido en la CIE-10 para designar la intoxicación de importancia clínica es el de intoxicación aguda (F1x.0), clasificado bajo la rúbrica "trastornos mentales y del comportamiento derivados del uso del alcohol" (F10). Por su parte, el DSM-V alinea el trastorno por abuso de alcohol con un modelo problemático de consumo que provoca un deterioro o malestar clínicamente significativo y que se manifiesta, al menos, por dos de los hechos siguientes en un plazo de 12 meses: consumo de alcohol con frecuencia en cantidades superiores o durante un tiempo más prolongado del previsto; deseo persistente o esfuerzos fracasados de abandonar o controlar el consumo de alcohol; inversión de mucho tiempo en las actividades necesarias para conseguir alcohol, consumirlo o recuperarse de sus efectos; ansias o un poderoso deseo o necesidad de consumir alcohol; consumo recurrente de alcohol que lleva al incumplimiento de los deberes fundamentales en el trabajo, la escuela o el hogar; consumo continuado de alcohol a pesar de sufrir problemas sociales o interpersonales persistentes o recurrentes, provocados o exacerbados por los efectos del alcohol; abandono o reducción de importantes actividades sociales, profesionales o de ocio; consumo recurrente de alcohol en situaciones en las que provoca un riesgo físico; se continúa con el consumo de alcohol a pesar de saber que se sufre un problema físico o psicológico persistente o recurrente probablemente causado o exacerbado por el alcohol; tolerancia, definida, a su vez, por la necesidad de consumir cantidades cada vez mayores de alcohol para conseguir la intoxicación o el efecto deseado o por una notable reducción de los efectos tras el consumo continuado de la misma cantidad de alcohol; abstinencia, manifestada por la presencia del síndrome de abstinencia característico del alcohol o por el consumo de alcohol (o de alguna sustancia muy similar, como una benzodiacepina) para aliviar o evitar los síntomas de abstinencia. La concurrencia de 2 ó 3 síntomas determina la calificación del abuso como leve, la de 4 ó 5 como moderado y la de 6 ó más como severo.

Considerando esa y otras referencias legales y doctrinales, existe un cierto consenso a la hora de presentar a la embriaguez o intoxicación etílica, genéricamente, como un estado fisiológico inducido por el consumo excesivo de alcohol y que conlleva una perturbación, más o menos extensa, del nivel de conciencia, de la cognición, de la percepción, del estado afectivo, del comportamiento o de otras funciones y respuestas fisiológicas o psicológicas, pudiendo llegar a provocar trastornos mentales de diversa intensidad o, incluso, la incapacidad de comprender y determinarse ${ }^{23}$. Estas consideraciones son perfectamente

\footnotetext{
23 Vid., por ejemplo, OTTATI FOLLE, Alcoholismo y Derecho penal, cit. nota $\mathrm{n}^{\circ} 10$, pp. 16 y ss.; ESCALANTE, La defensa del enfermo mental, cit. nota no 3, pp. 127 y 128; GONZÁLEZ R., Jenny C., Alcoholismo: factor generador de conductas criminógenas en el ámbito intrafamiliar, Caracas: Universidad Católica Andrés Bello, 2003, pp. 20 y ss.; ARTEAGA SÁNCHEZ, Alberto, Derecho penal venezolano, cit. nota $\mathrm{n}^{\circ} 4$, pp. 337 y ss.; CASAROTTI, Humberto, "Problemas que la drogas plantea al psiquiatra práctico", Revista de Psiquiatría de Uruguay, vol. 72 (2008), pp. 186 ss.; AGUILAR AVILÉS, Dager, "Análisis de algunas repercusiones jurídico penales y criminológicas de la embriaguez o intoxicación por la ingestión de alcohol", Contribuciones a las Ciencias Sociales, No 7 (2010), en: www.eumed.net/rev/cccss/07/daa3.htm [visitado el 22.07.2016].
} 
VÁSQUEZ-PORTOMEÑE, Fernando. "La circunstancia atenuante de embriaguez: una visión de sus elementos y requisitos en algunos sistemas penales iberoamericanos".

aplicables a los términos embriaguez o intoxicación contenidos en las normas que estamos analizando.

Cuestión distinta es la determinación de la clase concreta de embriaguez que fundamenta, en cada uno de los tres textos punitivos, la apreciación de la atenuante.

En Uruguay, el art. $46.4^{\circ}$ del Código penal contempla tres hipótesis de embriaguez que poseen esa eficacia: a) la voluntaria plena y no premeditada para cometer el delito; b) la culpable plena; y c) la semiplena determinada por caso fortuito o fuerza mayor.

En Venezuela, por el contrario, la jurisprudencia ha venido insistiendo en que todos los supuestos previstos en el art. 64 del texto punitivo lo son de embriaguez voluntaria y plena, total, entendiendo por tal aquella que compromete gravemente la consciencia o la libertad de los actos del sujeto ${ }^{24}$. Ese rasgo alcanza también a la embriaguez casual o excepcional (art. 64.5), dotada de una eficacia atenuante especial. Por lo que alcanzo a ver, el principal motivo de controversia en la literatura penal es la inclusión, en el propio art. 64, de la embriaguez patológica y de la crónica ${ }^{25}$.

Finalmente, en El Salvador la ingesta debe haberse iniciado por un acto voluntario, con conocimiento -cuando menos potencial- de que sus consecuencias podían derivar en afectaciones a bienes jurídicos ajenos, y, además, no revestir el carácter de plena ${ }^{26}$. La embriaguez "plena y fortuita", que produzca una perturbación de la conciencia capaz de anular toda capacidad de acción del sujeto que la padece, determina la apreciación de una eximente (art. 31 del Código penal).

2.2.2. El carácter "no preordenado" de la ingesta.

Es bien sabido que el consumo de alcohol incrementa la predisposición al descontrol o la permisividad con relación a las propias conductas ${ }^{27}$. Pues bien, en los países que estamos

${ }^{24}$ Vid. ARTEAGA SÁNCHEZ, Alberto, Derecho penal venezolano, cit., nota no 4, p. 338 y 339 . En la jurisprudencia pueden consultarse las siguientes sentencias de la Sala de Casación Penal del Tribunal Supremo de Justicia de Venezuela: 0243/C00-1396, de 3 de abril de 2001; 306/C09-214, de 27 de julio de 2010; 357/C10-073, de 6 de agosto de 2010; 495/C10-248, de 1 de diciembre de 2011; 634/C99-1376, de 11 de mayo.

${ }^{25}$ La cuestión de fondo es la de si dicho precepto establece o no un régimen específico, ajeno al concepto y disciplina general de la imputabilidad en Derecho penal. Quienes apuestan por la afirmativa no contemplan ninguna clase de restricciones en su aplicación, califican también, con arreglo a él, los supuestos de intoxicación que, en puridad, deberían resolverse como casos de inimputabilidad. Vid. los términos y alcance de este debate doctrinal en GONZÁLEZ R., Jenny C., Alcoholismo: factor generador de conductas criminógenas, cit., nota $\mathrm{n}^{\mathrm{o}} 23$, pp. 201 y ss., con indicaciones bibliográficas.

${ }^{26}$ Vid. las sentencias P1201-50-2009, del Tribunal de sentencia San Francisco Gotera, Departamento del Morazán, de 22 de junio de 2009, y 86-CAS-2011, de la Sala de lo Penal de la Corte Suprema de Justicia de El Salvador, de 25 de octubre de 2013.

${ }^{27}$ Esta cuestión ha sido examinadas con especial detenimiento en el ámbito de la violencia doméstica y de género. Vid., por ejemplo, LLORET IRLES, D., “Alcoholismo: una visión familiar”, Salud y Drogas, Vol. 1 No 1 (2001), pp. 113-128.; ZILBERMAN, Monica L.; BLUME, Sheila B., "Domestic violence, alcohol and substance abuse", Revista Brasileira de Psiquiatría, Vol. 27 (2005), pp. 51-55; MÚGICA SAN EMETERIO, Elisa, "El perfil psicológico de la víctima y el agresor", en: BOLDOVA PASAMAR, Miguel Ángel; RUEDA MARTÍN, María Ángeles (Coords.), La reforma penal en torno a la violencia doméstica y de género, 
Polít. crim. Vol. 12, No 23 (Julio 2017), Art. 11, pp. 409-427.

[http://www.politicacriminal.cl/Vol_12/n_23/Vol12N23A11.pdf]

analizando se excluye la apreciación de la embriaguez cuando el responsable había buscado colocarse en estado de intoxicación, por el consumo de bebidas alcohólicas, con el propósito de cometer un delito (embriaguez "preordenada"). Los Códigos penales de Uruguay y El Salvador, en concreto, hablan, por ese orden, de una "embriaguez voluntaria que no fuere premeditada para cometer el delito" (art. 46. 4") y de un "estado de intoxicación alcohólica o de otra índole que, sin ser preordenada al hecho, no llegue a tener plenitud de efectos sobre el sujeto" (art. 29. 1). El de Venezuela, por su parte, les atribuye directamente- efectos agravantes a los supuestos en que el sujeto había consumido alcohol "con el fin de facilitarse la perpetración del delito, o preparar una excusa" (art. 64. 1), que la doctrina asocia al tipo clásico de las acciones libera in causa ${ }^{28}$.

\subsubsection{La relación entre la embriaguez y la ejecución del delito.}

Como se desprende de su fundamento, lo que explica y da sentido a la atenuación no es la situación de intoxicación del sujeto en si misma, sino su conexión con la realización delictiva. La circunstancia requiere, entonces, que el delito se halle estrechamente vinculado a la intoxicación, pero no como forma de sufragar una posible adicción asociada a la misma, sino como una manifestación de la alteración que sufre el autor. Su estructura replica la relación que existe entre los dos elementos que fundamentan, en la concepción clásica, las alteraciones de la imputación: un presupuesto psiquiátrico y un déficit en las facultades volitivas y/o intelectivas ${ }^{29}$.

Dicho ello, conviene precisar que el vínculo existente entre la embriaguez y la ejecución delictiva presenta un doble carácter: temporal -puesto que la circunstancias se dirige a sujetos que, en el preciso momento de realizar el delito, sufren una perturbación que ha afectado de manera sustantiva a su consciencia y a su capacidad de autodominio ${ }^{30}$ y objetivo, en la medida en que, como ya se ha avanzado, los tres países abren la circunstancia a todos los delitos que puedan verse influidos por ella (lesiones, homicidio, amenazas, delitos contra la libertad sexual, delitos contra la propiedad, tenencia ilícita de armas... $)^{31}$. En esos términos, su ámbito de aplicación abarcará, además de a los delitos de

Barcelona: Bosch, 2006, pp. 325-338, p. 334; KLOSTERMANN, Keith; KELLEY, Michelle, "Alcoholism and Intimate Partner Violence: Effects on Children's Psychosocial Adjustment", International Journal of Environmental Research and Public Health, № 6 (2009), pp. 3156-3168; PASCUAL PASTOR, Francisco; REIG RUANO, Manuel; FONTOBA FERRÁNDIZ, Julio; GARCÍA DEL CASTILLO LÓPEZ, Álvaro, "Alcohol y violencia", Health and Addictions, $\mathrm{N}^{\circ} 1$ (2011), pp. 71-94.

${ }^{28}$ Vid. por todos ARTEAGA SÁNCHEZ, Derecho penal venezolano, cit. nota $\mathrm{n}^{\circ}$ 4, p. 340.

29 Vid. CORCOY BIDASOLO/MIR PUIG, Comentarios, cit. nota $\mathrm{n}^{\circ}$ 4, p. 232; ARIAS EIBE, Responsabilidad criminal, cit. nota n ${ }^{\circ}$ 5, p. 215; CASTELLÓ NICÁS, "Causas de inimputabilidad", cit. nota $\mathrm{n}^{\circ} 10$, pp. 423 y 430.

${ }^{30}$ Vid., en la jurisprudencia salvadoreña, las sentencias de la Sala de lo Penal de la Corte Suprema de Justicia 286-CAS-2011, de 25 de octubre de 2013, y 441-CAS-2009, de 6 de mayo de 2011.

31 Vid. ACOSTA, Carolina, Los trastornos mentales y la responsabilidad penal, en: http://maestriauba2010.blogspot.com.es/2011/08/monografia-los-trastornos-mentales-y-la.html [visitado el 24.07.2016]. La delincuencia asociada a los episodios de embriaguez o mera perturbación sin adicción presenta unos perfiles muy distintos de los de la motivada por la grave adicción del sujeto. Vid., en este sentido, OBREGÓN GARCÍA, "La eximente", cit. nota no 13, pp. 144-145. CASTELLÓ NICÁS se hace también eco de la distinción reflejada en el texto, cuando escribe que "es obvio que se puede matar, agredir a la libertad sexual de otro, o atentar contra cualquier bien jurídico, pero no 'a causa de su grave adicción', sino 
VÁSQUEZ-PORTOMEÑE, Fernando. "La circunstancia atenuante de embriaguez: una visión de sus elementos y requisitos en algunos sistemas penales iberoamericanos".

acción, a los omisivos. Así, por utilizar dos ejemplos sencillos, podrían beneficiarse de ella un sujeto alcoholizado que omitiese prestar socorro a la víctima de un accidente de coche provocado por él mismo o el controlador aéreo en estado de embriaguez que se ausentase de su puesto para beber y diese lugar a un grave accidente por no suministrar las informaciones pertinentes ${ }^{32}$.

\section{Delimitación de la atenuante frente a la eximente.}

Aunque los Códigos penales de Venezuela (art. 62) y Uruguay (art. 31) prevén eximentes de la responsabilidad penal relacionadas con la perturbación mental y la embriaguez completa, respectivamente, el único en el que la atenuante aparece como el alter ego, en términos de menor intensidad, de una eximente orientada a la embriaguez completa (art. 27.4) es el de El Salvador. Veámoslo con algún detalle.

Comenzando por la situación en Venezuela, aunque la jurisprudencia rechaza que la ebriedad pueda operar como eximente ${ }^{33}$, un sector doctrinal defiende la inclusión de algunas de sus modalidades en el art. 62 del Código penal, que excluye la responsabilidad penal de quien ejecuta la acción "hallándose dormido o en estado de enfermedad mental suficiente para privarlo de la conciencia o de la libertad de sus actos". Quienes lo integran apuntan, en concreto, a la crónica (cuando el alcoholismo se presenta con las características de una psicosis grave-delirium tremens, alucinosis...-), a la patológica y a la fortuita o accidental, que consiste en embriagarse a raíz de haber ingerido alcohol ignorando sus efectos, por haber incurrido en error de cálculo sobre su cantidado, en fin, por la acción de un tercero que sustituyó una bebida inocua por otra intoxicante ${ }^{34}$.

El Código penal uruguayo responde a un esquema similar. Reconoce como atenuante a la embriaguez plena voluntaria o culpable, así como a la semi-plena por fuerza mayor, derivando al art. 30 (eximente de "locura") la patológica-que encaja perfectamente en el sistema de imputabilidad mixto (psiquiátrico, psicológico y jurídico) descrito en dicho precepto $^{35}$ - y al 31 (eximente de "embriaguez") la completa determinada por fuerza mayor o caso fortuito.

En ambos países, como vemos, el legislador ha decidido condicionar la aplicación de la circunstancia a la demostración de que el sujeto se halla en un estado de embriaguez plena

estando bajo los efectos de una 'disminución de la imputabilidad' que condicione su estado psíquico". Vid. CASTELLÓ NICÁS, "Causas de inimputabilidad", cit. nota $\mathrm{n}^{\circ}$ 10, p. 446. En la jurisprudencia uruguaya pueden verse las sentencias del Tribunal de Apelaciones de lo Penal 96/2015, de 17 de abril (homicidio), 124/2013, de 20 de junio (homicidio), 18/2014, de 18 de febrero (robo, lesiones). En la de El Salvador las sentencias de la Sala de lo Penal de la Corte Suprema de Justicia 86-CAS-2011, de 25 de octubre de 2013 (agresiones sexuales), 188-CAS-2005, de 9 de enero de 2006 (lesiones) y 441-CAS-2009, de 6 de mayo de 2011 (lesiones).

32 De hecho, como señalan Moreno Carrasco y Rueda García, los casos de intoxicación plena se corresponderán, normalmente, "con meras omisiones" o "secuencias de hechos sumamente sencillas". Cfr. MORENO CARRASCO/RUEDA GARCÍA, Código penal, cit. nota nº 4, p. 173.

${ }^{33}$ Vid, por todos, ESCALANTE, La defensa del enfermo mental, cit. nota ${ }^{\circ} 3$, p. 124.

${ }^{34}$ Vid. CABALLERO FRÍAS, Problemas de culpabilidad, cit. nota ${ }^{\circ}$ 10, pp. 133-136; SCAPUSIO/PREZA RESTUCCIA/LANDEIRA, "Proyecto de reforma", cit. nota n ${ }^{\circ} 4$, pp. 246-247.

${ }^{35}$ Vid. OTTATI FOLLE, Alcoholismo y Derecho penal, cit. nota no 10, pp. 96 y 97. 
Polít. crim. Vol. 12, № 23 (Julio 2017), Art. 11, pp. 409-427.

[http://www.politicacriminal.cl/Vol_12/n_23/Vol12N23A11.pdf]

(y no semiplena, parcial, incompleta o relativa), lo que significa tanto como que su delimitación frente a las eximentes relacionadas con la ingesta de alcohol discurre sobre el plano de la modalidad de embriaguez de que se trate, no sobre el de la intensidad con que se compromete su conciencia o libertad.

El caso de El Salvador es distinto. Su sistema penal incluye una eximente (la de "grave perturbación de la conciencia") capaz de abarcar las intoxicaciones en que se constata una afectación de la capacidad de conciencia y/o voluntad tan intensa que el sujeto no está en disposición de comprender lo lícito de su acción u omisión o de determinarse de acuerdo con esa comprensión ${ }^{36}$, así como los estados de alcoholismo habitual que hayan desembocado en enfermedades mentales y lesiones cerebrales. La atenuante del art. 29.1 califica, por el contrario, estados de semi-imputabilidad o imputabilidad disminuida, merecedores de un menor de juicio de reproche (con relación a la capacidad de motivación del sujeto).

El legislador salvadoreño hace, pues, un uso lineal de los principios que informan y gradúan la capacidad de culpabilidad en Derecho penal, optando por articular respuestas diferenciadas en función de la mayor o menor importancia de los defectos de comprensión o adecuación de su conducta padecidos por el sujeto, como consecuencia de la intoxicación alcohólica $^{37}$. Con todo, hay que reconocer que hacer pivotar la apreciación de la atenuante o de la eximente, exclusivamente, sobre el grado de disminución de la imputabilidad depara notables dificultades en el terreno de la prueba ${ }^{38}$. Acreditarlo requerirá de una tarea valorativa a realizar por el juez o tribunal, que deberán proceder caso por caso, con el correspondiente asesoramiento técnico, examinando las consecuencias que la ingesta ha producido en el sujeto en función de sus características personales ${ }^{39}$.

\section{La atenuante analógica.}

Además de poseer una trascendencia práctica indudable, la delimitación entre la atenuante ordinaria y la analógica vinculadas a la embriaguez se implica con cuestiones relevantes de legalidad y tipicidad penales (como la exacta definición de sus respectivos ámbitos de aplicación), seguridad jurídica y, también, política criminal (pensando en el papel que debe asignársele a unas y otras en el sistema de las consecuencias jurídico-penales de la embriaguez). De los códigos penales examinados en este trabajo, los que admiten la

\footnotetext{
${ }^{36}$ Vid. MORENO CARRASCO/RUEDA GARCÍA, Código penal, cit. nota no 2, p. 172; SCAPUSIO/PREZA RESTUCCIA/LANDEIRA, "Proyecto de reforma", cit. nota n 4, pp. 246 y 247.

${ }^{37}$ Así lo señala expresamente la sentencia de la Sala de lo Penal de la Corte Suprema de Justicia 441-CAS2009, de 6 de mayo de 2011.

${ }^{38}$ Lo reconoce, por ejemplo, la sentencia del Tribunal de Apelaciones de lo Penal 18/2014, de 18 de febrero. Hace años que la psiquiatría ha comprobado la existencia de estados intermedios entre la plena imputabilidad y la inimputabilidad, entre los que se cuentan la intoxicación alcohólica semiplena y los trastornos que provoca, ocasionales o permanentes. Cfr. LANDAVERDE, Moris, "La responsabilidad penal del ebrio", Enfoque Jurídico, 2 de diciembre de 2014, en: http://www.enfoquejuridico.info/wp/archivos/687\#_ftn11 [visitado el 25.07.2016].

${ }^{39}$ Vid. CAIROLI MARTÍNEZ, "La capacidad”, cit. nota n 4, p. 899; VÁZQUEZ IRUZUBIETA, Carlos, Comentarios al Código penal, Madrid: Edersa, 2010, p. 137; CASTELLÓ NICÁS, "Causas de inimputabilidad", cit. nota $\mathrm{n}^{\mathbf{0}} 10$, p. 424. A las dificultades de esa tarea valorativa alude la sentencia 86-Cas2011, de 25 de octubre, de la Sala de lo Penal de la Corte Suprema de Justicia.
} 
VÁSQUEZ-PORTOMEÑE, Fernando. "La circunstancia atenuante de embriaguez: una visión de sus elementos y requisitos en algunos sistemas penales iberoamericanos".

posibilidad de construir atenuantes analógicas son el uruguayo (art. 46.13) y el salvadoreño (art. 29.5).

En Uruguay, el Tribunal de Apelaciones de lo Penal pone en relación la atenuante analógica con casos de embriaguez semiplena, voluntaria y no premeditada, siempre y cuando sirva para mitigar la agresividad del sujeto o para disminuir "la cantidad política del delito", 4 .

En El Salvador, en cambio, la jurisprudencia ha venido fijando el límite mínimo para su aplicación en la constatación de que el sujeto había consumido bebidas embriagantes en el momento de los hechos. En esa línea se sitúan, por ejemplo, las sentencias del Tribunal de Sentencia de San Salvador P0131-9-2001, de 14 de mayo de 2001 -que declara que "aunque no se haya graduado con precisión el grado de intoxicación alcohólica y la respectiva disminución de la psique de la persona", basta con que la prueba indique "de manera meridiana que estaba bajo los efectos del alcohol" para entender que "la persona ya no podría estar en la normalidad de sus facultades psíquicas" ${ }^{41}$, y del Tribunal de Sentencia de Chalatenango P0901-92-2001, de 22 de octubre, a cuyo tenor "aunque no se ha establecido con una prueba científica, cuál era el grado de intoxicación alcohólica en la que se encontraba el procesado..., en el desfile probatorio hubo testimonios que expresaron que el indiciado había ingerido bebidas embriagantes, sin llegar ésta a tener plenitud de efectos sobre la conciencia de los actos del mismo, interpretando tal situación este Tribunal en forma analógica como atenuante de la pena".

Teniendo en cuenta que el sentido de la atenuante ordinaria es, claramente, el de ponderar los efectos que produce la intoxicación en la imputabilidad, las formas de proceder que acabo de exponer podrían suscitar dudas. Cabría pensar, por ejemplo, que someter al mismo tratamiento (penológico) las intoxicaciones que afectan plena o, cuando menos, sensiblemente a la imputabilidad y aquellas otras en que existe una alteración menor, o en que lo único que puede demostrarse es la propia ingesta, redunda en una especie de fraude de ley, desde el momento en que la aplicación de la atenuante analógica no se seguiría del (mismo) principio esencial ${ }^{42}$. Además, en términos de seguridad jurídica, el criterio de la

\footnotetext{
${ }^{40}$ Vid., por ejemplo, la sentencia del Tribunal de Apelaciones de lo Penal 234/2013, de 31 de julio, que opta por su apreciación (como atenuante analógica) en un supuesto en que los informes periciales no pudieron acreditar si la clase de alcohol ingerida por el acusado (un "alcoholista intenso") había operado "como desinhibidor para la agresividad". Vid. además las siguientes sentencias, también, del Tribunal de Apelaciones de lo Penal: 252/2015, de 30 de noviembre; 311/2013, de 19 de septiembre; 335/2014, de 12 de noviembre; 210/2013, de 20 de junio; 234/2013, de 31 de julio; 49/2013, de 13 de marzo; 13/2015, de 18 de febrero; 340/2007, de 8 de octubre; 96/2015, de 17 de abril; 49/2013, de 13 de marzo; 252/2015, de 30 de septiembre; 174/2008, de 22 de julio.

${ }^{41}$ Vid. Cfr. MORENO CARRASCO/RUEDA GARCÍA, Código penal, cit. nota no 4, p. 182.

42 MORENO CARRASCO/RUEDA GARCÍA advierten que "la semejanza que ha de haber entre las atenuantes ya referenciadas y las circunstancias que se construyan a amparo de este precepto se centra en lo valorativo de unas y otras y los principios que las informan, no tanto en la equivocada idea de construir necesariamente estas circunstancias analógicas como s de una especie de atenuantes incompletas se tratara". Cfr. Código penal, cit. nota n ${ }^{\circ}$ 4, p. 181. En España diversas sentencias del Tribunal Supremo previenen sobre los riesgos de crear atenuantes incompletas a partir de una interpretación poco correcta de la llamada atenuante analógica: vid. STS de 20 de julio de 1998, STS de 1 de septiembre de 1999, STS de 19 de febrero de 1999 y STS de 8 de mayo de 2013.
} 
Polít. crim. Vol. 12, № 23 (Julio 2017), Art. 11, pp. 409-427.

[http://www.politicacriminal.cl/Vol_12/n_23/Vol12N23A11.pdf]

intensidad de la alteración de las capacidades volitivas y/o intelectivas del sujeto resulta mucho más operativo y practicable cuando se emplea únicamente para delimitar los ámbitos de la eximente y de la atenuante ordinaria. Mucho menos problemático resultaría, por ello, alinear la atenuante analógica con estados semejantes a la embriaguez, utilizando como referencia lo dispuesto en el DSM-V, sin reducir el requisito de la afección a la capacidad del sujeto para comprender lo ilícito del comportamiento y actuar conforme a esa comprensión.

\section{Conclusiones.}

En las páginas que anteceden se han contrastado los requisitos técnicos que los Códigos penales de Uruguay, El Salvador y Venezuela exigen para hacer uso de la atenuante de embriaguez.

$\mathrm{Su}$ fundamento siempre viene asociado a una alteración de la imputabilidad del sujeto, definiéndose su ámbito de aplicación en función de la incidencia de la intoxicación en las capacidades psíquicas. Por ello, para apreciarla no se considera suficiente con que se acredite el estado de ebriedad del sujeto, sino que se requiere que la disminución de las capacidades esté presente, precisamente, en el momento de realizar el delito.

Otro rasgo común a los tres textos legales es que dejan traslucir la voluntad de diversificar el tratamiento penal de los estados relacionados con la ingesta de bebidas alcohólicas, para incluir en el campo de las eximentes algunas tipologías de intoxicación plena, así como los supuestos en que el sujeto acusa déficits asociados al consumo y que condicionan absolutamente su imputabilidad. En Uruguay y Venezuela la relación entre dichas eximentes y la atenuante de embriaguez discurre, sin embargo, sobre el plano de la modalidad de embriaguez de que se trate, no sobre el de la intensidad con que se compromete la conciencia o libertad del sujeto.

Por otra parte, aunque cada legislador nacional recurre a una redacción o técnica descriptiva distinta, todos optan por definirla incorporando, como características esenciales, la influencia de la embriaguez sobre la imputabilidad y su no preordenación a la actividad delictiva. Con respecto al primer elemento, los de El Salvador y Uruguay la caracterizan expresamente como plena o semiplena, dependiendo de las modalidades de embriaguez de que se trate, en tanto que el venezolano acude a una fórmula menos precisa (embriaguez "causante de una perturbación mental"), que la jurisprudencia asocia, asimismo, con las intoxicaciones de carácter pleno.

A continuación se reflejan en sendas tablas los resultados del trabajo en relación con la construcción legal de la atenuante (tabla $\mathrm{n}^{\circ} 1$ ) y con sus relaciones con las eximentes vinculadas a la embriaguez (tabla $\left.n^{\circ} 2\right)$. 
VÁSQUEZ-PORTOMEÑE, Fernando. "La circunstancia atenuante de embriaguez: una visión de sus elementos y requisitos en algunos sistemas penales iberoamericanos".

Tabla 1

\begin{tabular}{|c|c|c|c|c|c|}
\hline PAÍS & NORMA & REQUISITO 1 & REQUISITO 2 & REQUISITO 3 & REQUISITO 4 \\
\hline VENEZUELA & ART. 64 CP & EMBRIAGUEZ & $\begin{array}{c}\text { NO BUSCADA } \\
\text { PARA } \\
\text { FACILITAR EL } \\
\text { DELITO O } \\
\text { PREPARAR UNA } \\
\text { EXCUSA }\end{array}$ & $\begin{array}{l}\text { CAUSANTE DE } \\
\text { UNA } \\
\text { PERTURBACIÓN } \\
\text { MENTAL }\end{array}$ & $\begin{array}{c}\text { EL SUJETO NO } \\
\text { SABÍA NI ERA } \\
\text { NOTORIO EN SU } \\
\text { ENTORNO QUE } \\
\text { LA } \\
\text { EMBRIAGUEZ } \\
\text { LE HACÍA } \\
\text { PROVOCADOR } \\
\text { Y } \\
\text { PENDENCIERO }\end{array}$ \\
\hline URUGUAY & ART. $46.4^{\circ} \mathrm{CP}$ & $\begin{array}{c}\text { EMBRIAGUEZ } \\
\text { VOLUNTARIA } \\
\text { (1), CULPABLE } \\
\text { (2) O } \\
\text { PRODUCIDA } \\
\text { POR FUERZA } \\
\text { MAYOR O CASO } \\
\text { FORTUITO (3) } \\
\end{array}$ & $\begin{array}{c}\text { NO } \\
\text { PREMEDITADA } \\
\text { PARA } \\
\text { COMETER EL } \\
\text { DELITO (1) (2) }\end{array}$ & $\begin{array}{l}\text { PLENA (1) (2) } \\
\text { SEMIPLENA (3) }\end{array}$ & - \\
\hline EL SALVADOR & ART. $29.1 \mathrm{CP}$ & $\begin{array}{l}\text { ESTADO DE } \\
\text { INTOXICACIÓN } \\
\text { ALCOHÓLICA }\end{array}$ & $\begin{array}{c}\text { NO } \\
\text { PREORDENADA } \\
\text { AL HECHO }\end{array}$ & $\begin{array}{l}\text { SIN PLENITUD } \\
\text { DE EFECTOS EN } \\
\text { EL SUJETO }\end{array}$ & - \\
\hline
\end{tabular}

Tabla 2

\begin{tabular}{|c|c|c|c|}
\hline PAÍS & ATENUANTE & $\begin{array}{c}\text { EXIMENTE } \\
\text { CORRELATIVA }\end{array}$ & $\begin{array}{c}\text { EXIMENTE CAPAZ DE } \\
\text { CUBRIR ALGUNOS } \\
\text { CASOS DE EMBRIAGUEZ }\end{array}$ \\
\hline VENEZUELA & EMBRIAGUEZ & - & LOCURA \\
\hline URUGUAY & EMBRIAGUEZ & $\begin{array}{c}\text { EMBRIAGUEZ } \\
\text { COMPLETA }\end{array}$ & $\begin{array}{c}\text { G } \\
\text { EL SALVADOR }\end{array}$ \\
\hline $\begin{array}{c}\text { INFERIORIDAD PSÍQUICA } \\
\text { POR INTOXICACIÓN }\end{array}$ & - & $\begin{array}{c}\text { RAVE PERTURBACIÓN } \\
\text { DE LA CONCIENCIA }\end{array}$ \\
\hline
\end{tabular}


Polít. crim. Vol. 12, № 23 (Julio 2017), Art. 11, pp. 409-427.

[http://www.politicacriminal.cl/Vol_12/n_23/Vol12N23A11.pdf]

\section{BIBLIOGRAFÍA}

AGUILAR AVILÉS, Dager, "Análisis de algunas repercusiones jurídico penales y criminológicas de la embriaguez o intoxicación por la ingestión de alcohol", Contribuciones a las Ciencias Sociales, $\mathrm{N}^{\mathrm{o}} 7$ (2010), en: www.eumed.net/rev/cccss/07/daa3.htm [visitado el 22.07.2016].

ARIAS EIBE, Manuel José, Responsabilidad criminal. Circunstancias modificativas y su fundamento en el Código penal. Una visión desde la doctrina y la jurisprudencia del Tribunal Supremo, Barcelona: Bosch, 2007.

ARROYO DE LAS HERAS, Alfonso; MUÑOZ CUESTA, Javier; GOYENA HUERTA, Jaime, Las circunstancias atenuantes en el Código penal de 1995, Pamplona: Aranzadi, 1997.

CAIROLI MARTÍNEZ, Milton, "La capacidad de culpabilidad y su exclusión (inimputabilidad)", en: ARROYO ZAPATERO, Luis Alberto; BERDUGO GÓMEZ DE LA TORRE, Ignacio (Coords.), Homenaje al Dr. Marino Barbero Santos:"in memorian", Salamanca: Universidad de Salamanca, 2001, pp. 896-906.

CASAROTTI, Humberto, "Problemas que la drogas plantea al psiquiatra práctico", Revista de Psiquiatría de Uruguay, Vol. 72 (2008), pp. 186-197.

CASTELLÓ NICÁS, Nuria, "Causas de inimputabilidad: drogadicción", Estudios de Derecho Judicial, N ${ }^{\circ} 110$ (2006), pp. 369-450.

CATALÁ MIÑANA, Alba; LILA, Marisol; OLIVER, Amparo, "Consumo de alcohol en hombre penados por violencia contra la pareja: factores individuales y contextuales", Adicciones, Vol. $25 \mathrm{~N}^{\circ} 1$ (2013), pp. 19-28.

CHIOSSONE, Tulio, Manual de Derecho penal venezolano, Caracas: Universidad Central de Venezuela, 1981.

CORCOY BIDASOlO, Mirentxu; MIR PUIG, Santiago (Dirs.), Comentarios al Código penal. Reforma LO 5/2010, Valencia: Tirant lo Blanch, 2011.

DOLD, Dennis, "Die actio libera in causa als Sonderfall der mittelbaren Täterschaft", Goltdammer's Archiv für Strafrecht, Vol. 155, № 7 (2008), pp. 427-441.

ECHEBURÚA ODRIOZOLA, Enrique, "Tratamiento psicológico a los hombres violentos contra la pareja", Cuadernos de Derecho Judicial, N 2 (2005), pp. 157-178.

ESCALANTE, Ramón A., La defensa del enfermo mental en el nuevo proceso penal venezolano, Caracas: Vadell Hermanos Editores, 2001.

GARCÍA PABLOS DE MOLINA, Antonio, Criminología. Una introducción a sus fundamentos teóricos, $7^{\mathrm{a}}$ ed., Valencia: Tirant lo Blanch, 2013.

GELLES, Richard; STRAUS, Murray, Intimate violence. The causes and consequences of abuse in the American family, Nueva York: Simon \& Schuster, 1988.

FRÍAS CABALLERO, Jorge, Problemas de culpabilidad en el Código penal venezolano, Caracas: Editores individuales 3, 1988.

JOSHI JUBERT, Ujala, La doctrina de la "actio libera in causa" en Derecho penal, Barcelona: Bosch, 1992.

KLOSTERMANN, Keith; KELLEY, Michelle, "Alcoholism and Intimate Partner Violence: Effects on Children's Psychosocial Adjustment", International Journal of Environmental Research and Public Health, № 6 (2009), pp. 3156-3168. 
VÁSQUEZ-PORTOMEÑE, Fernando. "La circunstancia atenuante de embriaguez: una visión de sus elementos y requisitos en algunos sistemas penales iberoamericanos".

LANDAVERDE, Moris, "La responsabilidad penal del ebrio", Enfoque Jurídico, 2 de diciembre de 2014, en: http://www.enfoquejuridico.info/wp/archivos/687\#_ftn11 [visitado el 25.07.2016].

LAURENZO COPELLO, Patricia, "Violencia de género y derecho penal de excepción: entre el discurso de la resistencia y el victimismo punitivo", Cuadernos de Derecho judicial, $\mathrm{N}^{\circ} 9$ (2007), pp. 31-74.

LLORET IRLES, D., “Alcoholismo: una visión familiar”, Salud y Drogas, Vol. 1 № 1 (2001), pp. 113-128.

LÓPEZ BARJA DE QUIROGA, Jacobo, Tratado de Derecho penal. Parte General, Madrid: Civitas, 2010.

LORENZO SALGADO, José Manuel, "Imputabilidad, suspensión de la ejecución de la pena y cumplimiento de la condena", en: BECOÑA IGLESIAS, Elisardo; RODRÍGUEZ LÓPEZ, Antonio; SALAZAR BERNARD, Isabel (Coord.), Drogodependencias V. Avances 1999, Santiago de Compostela: Universidad de Santiago de Compostela, 1999, pp. 15-55.

MARÍN DE ESPINOSA CEBALLOS, Elena Blanca, en: ZUGALDÍA ESPINAR, José Miguel (Dir.), Derecho penal, Parte General, $2^{\mathrm{a}}$ ed., Valencia: Tirant lo Blanch, 2004.

MARLATT, Gordon Alan; ROSENHOW, Damaris, "Cognitive processes in alcohol use: Expectancy and the balanced placebo design”, en: MELLO, Nancy (Ed.), Advances in substance abuse: Behavioural and biological research, Greenwich: JAI Press, 1980, pp. 159-199.

MARTÍNEZ GARAY, Lucía, La imputabilidad penal: concepto, fundamento, naturaleza jurídica y elementos, Valencia: Tirant lo Blanch, 2005.

MENDOZA TROCONIS, José Rafael, Curso de Derecho penal venezolano: Parte General, $7^{\mathrm{a}}$ ed., Caracas: Librería Destino, 1996.

MORENO CARRASCO, Francisco; RUEDA GARCÍA, Luis, Código penal de El Salvador comentado, t. I, San Salvador: Consejo Nacional de la Judicatura, 2011.

MÚGICA SAN EMETERIO, Elisa, "El perfil psicológico de la víctima y el agresor", en BOLDOVA PASAMAR, Miguel Ángel: RUEDA MARTÍN, María Ángeles (Coords.), La reforma penal en torno a la violencia doméstica y de género, Barcelona: Bosch, 2006, pp. 325-338.

OBREGÓN GARCÍA, Antonio, "La eximente del art. 20.2, inciso 1', CP: Estado de intoxicación plena por consumo de alcohol u otras drogas", Estudios de Derecho Judicial, No 110 (2006), pp. 137-218.

OTTATI FOLLE, Amadeo, Alcoholismo y Derecho penal, Montevideo: Amalio M. Fernández, 1975.

PADILlA ALBA, Herminio Ramón, "Comentario al art. 21, 2a del Código penal", en: COBO DEL ROSAL, Manuel (Dir.), Comentarios al Código penal, Tomo II, Madrid: Edersa, 1999, pp. 681-688.

Exención y atenuación de la responsabilidad penal por consumo de drogas, Granada: Comares, 2001.

PASCUAL PASTOR, Francisco; REIG RUANO, Manuel; FONTOBA FERRÁNDIZ, Julio; GARCÍA DEL CASTILLO LÓPEZ, Álvaro, "Alcohol y violencia”, Health and Addictions, $\mathrm{N}^{\mathrm{o}} 1$ (2011), pp. 71-94. 
Polít. crim. Vol. 12, № 23 (Julio 2017), Art. 11, pp. 409-427.

[http://www.politicacriminal.cl/Vol_12/n_23/Vol12N23A11.pdf]

PUENTE SEGURA, Leopoldo, Circunstancias eximentes, atenuantes y agravantes de la responsabilidad criminal, Madrid: Colex, 1997.

QUIGLEY, Brian; LEONARD, Kenneth, "Alcohol Use and Violence Among Young Adults", Alcohol Research \& Health, Vol. 38 No 4 (2005), pp. 191-194.

ROMÁN PINA-FUSTER, Román, Embriaguez, alcoholismo y Derecho penal, Barcelona: Bosch, 2000.

ROPERO CARRASCO, Julia; ZAMORANO MORENO, Pilar, "Las circunstancias atenuantes de la responsabilidad penal”, Studia Carande, Vol. 5 (2000), pp. 115-140.

RUIZ PÉREZ, Isabel; BLANCO PRIETO, Pilar; VIVES CASES, Carmen, "Violencia contra la mujer en la pareja: determinantes y respuestas sociosanitarias", Gaceta Sanitaria, Vol. 18 (2004), pp. 4-12.

SILVA SÁNCHEZ, Jesús María, “La estructura de la 'actio libera in causa' en los delitos cometidos bajo un síndrome de abstinencia de drogas (Una visión crítica de la última doctrina jurisprudencial), La Ley, $\mathrm{N}^{\circ} 1$ (1988), pp. 910-918.

SCAPUSIO, Beatriz, PREZA RESTUCCIA, Dardo, LANDEIRA, Raquel, "Proyecto de reforma del proceso penal", Revista de la Facultad de Derecho de la Universidad de la República, № 27 (2008-2009), pp. 237-252.

SUÁREZ-MIRA RODRÍGUEZ, Carlos, La imputabilidad del consumidor de drogas, Valencia: Tirant lo Blanch, 2000.

VALLE MUÑIZ, José Manuel; QUINTERO OLIVARES, Gonzalo, en: QUINTERO OLIVARES, Gonzalo (Dir.), Comentarios al Nuevo Código Penal, Pamplona: Aranzadi, 1996.

VÁZQUEZ IRUZUBIETA, Carlos, Comentarios al Código penal, Madrid: Edersa, 2010.

ZILBERMAN, Monica L.; BLUME, Sheila B., "Domestic violence, alcohol and substance abuse”, Revista Brasileira de Psiquiatría, Vol. 27 (2005), pp. 51-55. 